\title{
Fach- und Personalnachrichten.
}

Professor Zange, Jena hat den an ihn ergangenen Ruf nach Graz als Nachfolger von Professor Habermann angenommen.

Privatdozent Dr. Amersbach, Freiburg i. Br. wurde zum nichtplanmäßigen außerordentlichen Professor ernannt.

Professor Man asse, Würzburg und Professor Heine, München wurden zu etatsmäßigen ordentlichen Professoren ernannt.

Dem Privatdocenten Dr. Klestadt, Breslau wurde die Dienstbezeichnung außerordentlicher Professor verliehen.

Am 3. September starb der außerordentliche Professor Dr. J. Katzenstein, dem unsere Disziplin bekanntlich eine größere Reihe vortrefflicher Arbeiten aus dem Gebiete der Phonetik verdankt, im Alter von 58 Jahren.

Privatdocent Dr. Erich Ruttin, Wien erhielt den Titel eines außerordentlichen Professors.

Professor Dr. Car1. Schäfer, Berlin erhielt einen Lehrauftrag für Psycho-Physiologie des Gehörs.

Der Anzeigenteil des ersten Heftes dieses Bandes enthält eine dringende Bitte der Univ.-Ohren- und Kehlkopfklinik in Kiel um Unterstützung zur Schaffung einer Fachbibliothek; wir unterstützen diesen Notschrei und bitten die Herren Kollegen, Bücher und Zeitschriftenserien, die sie entbehren können, der Kieler Klinik billig zur Verfügung zu'stellen. 